\title{
DIMENSÕES HISTÓRICAS DA ESCOLARIZAÇÃO NO MEIO RURAL E URBANO BRASILEIRO: UM ESTUDO NOS MUNICÍPIOS DE ARAGUARI, UBERLÂNDIA E PATOS DE MINAS
}

\author{
Astrogildo Fernandes da Silva Júnior ${ }^{1}$ \\ José Josberto Montenegro Sousa ${ }^{2}$
}

\begin{abstract}
RESUMO
Este texto apresenta os resultados de uma pesquisa apoiada pela Pró Reitoria de Pós Graduação da Universidade Federal de Uberlândia - PROPP/UFU. O objetivo é compreender o processo de escolarização no meio rural e urbano nos municípios de Araguari, Uberlândia e Patos de Minas, localizados na região do Triângulo Mineiro e Alto Paranaíba no estado de Minas Gerais, Brasil. Verificou-se que ao longo da história da educação brasileira, a educação dos grupos menos favorecidos foi negligenciada pelo Estado, e pôde-se perceber que, no meio rural, isso se manifestou de forma mais intensa. Constatou-se que o processo de escolarização, no lócus da pesquisa, revelou aproximações da história da educação brasileira, evidenciando a interdependência entre "local" e "global".
\end{abstract}

Palavras-Chave: Escolarização; meio rural; meio urbano.

\section{HISTORICAL DIMENSIONS OF BRAZILIAN RURAL AND URBAN AREA EDUCATION: A STUDY DEVELOPED IN ARAGUARI, UBERLÂNDIA AND PATOS DE MINAS CITIES}

\begin{abstract}
This text presents the results of a research supportted by the Pro-Reitoria de Pesquisa e Pós-Graduação da Universidade Federal de Uberlândia - PROPP/UFU. The aim is to comprehend the process of education in the rural and urbar áreas from Araguari, Uberlândia and Patos de Minas Cities, located in Triângulo Mineiro and Alto Paranaíba regions in Minas Gerais State, Brazil. It was observed that along Brazilian educational history, education to less income people was neglected by the State and also it could be observed that in the rural area the abandon was more intense. Taking together, it could be observed that the education process in the locus of the research was similar to the Brazilian education history, making evident the interdependence between the microenvironment and the whole country.
\end{abstract}

Keywords: Professor education; identities; rural and urban schools. 


\title{
Introdução
}

\begin{abstract}
Educar implica que os educandos captem e aprendam as maneiras de pensar, de sentir e de agir que estão em circulação na cultura (aí está a reprodução), mas educar não pode inibir a produção da existência pelas novas gerações, que se faz à maneira de um garimpo: trata-se de extrair, de explorar e de construir também a partir da garimpagem, a produção social.

(José Carlos de Souza Araújo, 2007).
\end{abstract}

Para iniciar este texto, escolhemos esse trecho inspirador do professor José Carlos de Souza Araújo, que nos instiga a pensar sobre a importância da educação no sentido da reprodução e da produção da cultura. Essa afirmação nos faz lembrar Hanna Arendt (1972), que, em sua obra Entre o passado e o futuro, afirma que a educação, no sentido amplo da palavra, está entre as atividades mais elementares e necessárias da sociedade humana. Os pais, ao introduzirem seus filhos no mundo, assumem, ao mesmo tempo, uma dupla responsabilidade: pela vida, pelo desenvolvimento da criança e pela continuidade do mundo. Uma das funções da escola é de conservação, no sentido de preservação. Faz parte da essência da atividade educacional, cuja tarefa é sempre abrigar e proteger alguma coisa - a criança contra o mundo, o mundo contra a criança.

Essa ideia justifica o fenômeno da escolarização no século XX. A educação escolar passou a ser um direito universal dos homens. O mundo contemporâneo tornou-se impensável sem a escola. Nesse cenário, o papel da educação escolar e de todos os mecanismos educativos é a transmissão, a preservação da experiência humana entendida como cultura e também de produção de novos conhecimentos. Dessa forma, algumas questões tornam-se recorrentes: Como se deu o processo de escolarização no Brasil ao longo da história? A educação escolar, como direito universal dos homens, foi acessível a todas as classes sociais? Como se efetivou nos espaços rurais e urbanos?

Com o intuito de buscar possíveis respostas para os questionamentos supracitados, empreendemos um estudo bibliográfico sobre a história da educação no Brasil, mais especificamente, nos municípios de Araguari, Uberlândia e Patos Minas, localizados na região do Triângulo Mineiro e Alto Paranaíba, estado de Minas Gerais. A escolha dos municípios se deu por terem sido lócus de uma pesquisa realizada com apoio da Pró Reitoria de Pesquisa e Pós Graduação da Universidade Federal de Uberlândia - PROPP UFU.

\section{Retrocedendo o olhar...}

A vinda da família Real para o Brasil, em 1808, é considerada por Zotti (2004), como fator histórico fundamental para as mudanças relacionadas à educação. A vida urbana cresceu vertiginosamente, o Rio de Janeiro, capital do Brasil, tornou-se o centro intelectual do país. Porém mantinha-se o desinteresse completo pela educação do povo (ensino primário), ficando explícito que o objetivo era a educação para a elite, pois a preocupação era exclusivamente com o ensino superior.

Em 1822, formalizou-se o processo de independência política do Brasil, iniciado com a vinda da família real, que pode ser considerado como um empreendimento da classe dominante. Em 1824, foi outorgada a primeira Constituição brasileira, pela qual, no Art. $179, \S 32$, registrava que a instrução primária seria gratuita a todos os cidadãos. Para Zotti (2004), mesmo sendo significativo estar prevista a gratuidade do ensino primário, o quadro 
real não se alterou, pois a Constituição não apresentou meios para o cumprimento desse dispositivo. Permaneceu, assim, uma educação conduzida de acordo com os interesses da classe dirigente, uma educação elitista.

De acordo com Azevedo (1976), a educação brasileira, no período imperial, revelou a continuidade de uma estrutura social e econômica e do desenvolvimento do "tipo de cultura" colonial, produto de uma civilização fundada na escravidão. O objetivo da instrução era inculcar nos cidadãos as bases da ordem "natural" fundamentada na propriedade. Era tarefa da instrução pública convencer de que todos os homens são iguais quanto é possível ser. Para o autor, era papel da escola fazê-los compreender que, na realidade, não poderiam ser iguais, nem da ordem da natureza e nem da ordem social, uma vez que eram "naturalmente" desiguais.

Em 1889, foi proclamada a República no Brasil. Para a Zotti (2004), assim como ocorreu na abertura dos portos (1808) e na independência do Brasil (1822), a República nada mais foi que o reordenamento do Estado, que estava se tornando obsoleto ante a nova realidade econômica e política, de acordo com os interesses das elites. No início desse período, insistiu-se no discurso da necessidade da desanalfabetização e extensão da escola elementar para o povo, como um caminho para resolver as mazelas do país. Mas, na primeira fase da República, conhecida como "café com leite"3, as oligarquias defenderam um perfil ruralista para o país. De acordo com a autora, para os defensores dessa sociedade, a educação continuava como artigo de luxo restrito às classes favorecidas.

O texto da primeira Constituição da República brasileira, de 1891, reafirmava a descentralização escolar já definida desde 1834. Foi deferida aos estados a atribuição do ensino primário, dando-lhe o direito de organizar seus sistemas escolares, sem fixar as diretrizes de uma política de educação nacional. Para Romanelli (1998), esse período consagrou o sistema dual de ensino, que vinha mantendo desde o Império: uma educação para a classe dominante (escolas secundárias e superiores) e a educação do povo (escola primária e profissional). Segundo Faria Filho (1996), nos anos iniciais da República brasileira, assim como no período imperial, a escola pública primária que existia era aquela organizada pela própria população, contando, algumas vezes, com subvenções do Estado. Funcionavam em salões de igrejas, nas casas de professores, isto é, caracterizadas pela precariedade.

\section{A escolarização nos municípios investigados no período da Primeira República}

Ao determos nosso olhar nos municípios investigados, ao longo desse período, registramos as primeiras iniciativas da educação escolar. De acordo com Silva Júnior (2007), no município de Araguari, em 1896, com a instalação da Estação de Passageiro da Cia Mogiana de Estrada de Ferro, foram construídas três escolas para atender os filhos de ferroviários: a Escola Carmélia Dutra, que oferecia a educação primária, para meninos e meninas, geralmente, filhos de ferroviários; a Escola Profissionalizante, que atendia meninos, com uma educação voltada para formar mão de obra para a própria ferrovia e a Escola Técnica Feminina - ETEF, que atendia a filhas de ferroviários. A Lei 63, de 30 de agosto de 1898, regulou a instrução primária e secundária, sendo seis urbanas e seis rurais. Já em 17 de novembro de 1908, o Decreto Estadual n. 2.297 criou o Grupo Escolar de Araguary, primeira escola pública da cidade.

Sobre o município de Uberlândia, segundo Gatti, Inácio Filho e Gatti Júnior (2011), a instrução escolar foi uma preocupação de seus habitantes. Em 1835, foi instalada a primeira escola primária, por Felizberto Alves Carrejo, em sua própria residência, na fazenda Tenda, local denominado "Povoado dos Carrejos". Em 1860, foi instalada a 
primeira escola provincial pública. O primeiro estabelecimento de ensino secundário da cidade foi o Colégio Uberabinhense, inaugurado em 5 de julho de 1897. Em 1907, foi fundado o Externato Carvalho Brito, dirigido pelo professor Leôncio do Carmo Chaves de Brito, destinado ao ensino primário. No mesmo ano, foi implantado o Colégio Bandeirante e em 1908, o Colégio Mineiro. Em 1912, foi criada a instituição particular, Gymnásio do Uberabinha. Em 1915, foi instalado o Grupo Escolar Júlio Bueno Brandão.

De acordo com Coelho (2007), em Patos de Minas, no início do século XX, a população patense não podia vangloriar-se da instrução que era oferecida, pois beneficiava, em sua grande maioria, as classes mais favorecidas, apesar de o governo da província ter oficializado o ensino em 1853, quando foi criada uma escola primária na freguesia de Santo Antônio dos Patos. Mesmo com o discurso dos republicanos, sobre a importância da educação como caminho de se chegar ao progresso, Coelho (2007), informa que a situação educacional em Patos de Minas era bastante precária, pois havia poucas escolas instaladas. Em julho de 1917, fundou-se o Grupo Escolar Marcolino de Barros, considerado acontecimento notável na história da instrução primária da cidade, uma vez que simbolizava o avanço para o progresso.

Por sua vez, no que se refere à educação no meio rural brasileiro, prevalecia o descompromisso do poder público. Segundo Arroyo, Caldart e Molina (2004), a escola, no meio rural, foi tratada como resíduo do sistema educacional. Conforme Leite (1999),

\begin{abstract}
A educação rural no Brasil, por motivos socioculturais, sempre foi relegada a planos inferiores, e teve por retaguarda ideológica o elitismo acentuado do processo educacional, aqui instalado pelos jesuítas e a interpretação político-ideológica da oligarquia agrária conhecida popularmente na expressão: "gente da roça não carece de estudos. Isso é coisa de gente da cidade". (anônimo) (p. 14).
\end{abstract}

A escola rural, no Brasil, foi construída tardiamente e sem o apoio necessário por parte do Estado para que se desenvolvesse. Não se constituiu, historicamente, em um espaço prioritário para uma ação planejada e institucionalizada do Estado Brasileiro. Isso privou a população do campo, sobretudo a classe trabalhadora, de ter acesso às políticas e aos serviços públicos em geral, o que contribuiu para o processo do êxodo rural.

De acordo com Zotti (2004), as transformações desencadeadas a partir dos anos de 1910 foram consolidadas por volta de 1920. À época, o Brasil passou a contar com um razoável parque industrial, emergiu uma burguesia industrial, proletariado e classe média, marcando o declínio das oligarquias cafeeiras e a ascensão de uma sociedade semiindustrial. Nesse contexto, as novas forças sociais influenciaram a sociedade brasileira em vários aspectos, especialmente a educação. Para a autora, os anos de 1920 foram caracterizados pelo entusiasmo na educação e por frequentes reformas, tais como: Sampaio Dória (São Paulo, 1920); Lourenço Filho (Ceará, 1923), Anísio Teixeira (Bahia, 1925), Francisco Campos e Mário Casassanta (Minas Gerais, 1927), Fernando de Azevedo (Distrito Federal, 1928) e Carneiro Leão (Pernambuco, 1928). "A política educacional brasileira, até então voltada para o ensino superior, sofre pressões sociais que defendem a necessidade de pensar o ensino popular". (ZOTTI, 2004, p. 70). De acordo com a autora, o censo de 1920 revela que de 6.582.017 (seis milhões, quinhentos e oitenta e duas mil e dezessete) crianças em idade escolar, apenas 1.249.444 (um milhão, duzentos e quarenta e nove mil e quatrocentos e quarenta e quatro), o que significa que $19 \%$, recebiam algum ensino, e registrava-se que $75 \%$ dos adolescentes e adultos brasileiros eram analfabetos.

Quanto à realidade da educação escolar no meio rural, Araújo (2006) afirma que, desde o século XIX, já se evidenciavam intenções pontuais de dotar as populações rurais 
de escolas, Mas, somente a partir de 1930, ocorreram programas de escolarização relevantes para as populações rurais. Porém os resultados práticos ainda não se manifestaram inteiramente, no sentido de fornecer uma conformação especial às instituições escolares. Segundo a autora, nos anos de 1930, a formação do professor para o ensino rural era citadina. Era necessário, pois, criar um tipo de professor para o meio rural. A escola normal rural deveria formar um profissional entendido de agricultura, de enfermagem, ser um incentivador do progresso. Consoante com Araújo (2006), no Ceará, foi fundada a primeira Escola Normal Rural do Brasil. Juazeiro do Norte foi o município pioneiro com o papel de levar a "luz"do conhecimento para as terras secas dos campos cearenses. A fundação de uma escola em defesa de uma ação educadora que atingisse os sertões cearenses era amparada por educadores como Lourenço Filho e Sud Mencci. Ainda conforme Araújo (2006), as professoras formadas nas escolas normais rurais cearenses buscaram fazer o que podiam para realizar a "missão" educativa. Na prática, a educação no campo em quase nada foi alterada.

Para Silva (Silva et.al., 2008), ao longo do processo de reforma de ensino no Estado de Minas Gerais, em 1927, fortaleceu-se o debate que defendia o dualismo na educação mineira. A proposta era de um modelo de escola para a cidade e outro para o meio rural, e neste havia dois posicionamentos: enquanto um grupo defendia que a escola deveria ensinar a ler e a escrever nos dois primeiros anos e, nos dois anos seguintes, ensinar técnicas agrícolas; o outro grupo propunha uma escola que tivesse um calendário adaptado ao meio rural, mas que ensinasse o mesmo que no meio urbano. Ambos os grupos concordavam em que o papel da escola era diminuir o êxodo rural. Podemos observar que a preocupação não era com um ensino de qualidade, mas com o êxodo rural e suas consequências. $\mathrm{O}$ intuito do ensino oferecido era acabar com o analfabetismo e tornar o cidadão do campo "civilizado". Segundo Silva (Silva et.al., 2008), por volta de 1930, a educação escolar, no meio rural em Minas Gerais, tinha a função de ensinar hábitos de higiene e outros valores. Aprender a ler e escrever ficava relegado a segundo plano.

$\mathrm{Na}$ cidade de Araguari, no final dos anos de 1920, foram instaladas duas instituições de ensino moldadas na formação religiosa: O Colégio Sagrado Coração de Jesus e o Colégio Regina Pacis. Segundo Silva Júnior (2007), as duas instituições foram marcos no setor educacional da cidade, sendo referência intelectual e cultural por várias décadas, refletindo uma época em que a educação escolar era, extremamente, elitizada. $\mathrm{Na}$ educação pública, de acordo com o autor, em 1927, foram inauguradas as novas instalações do Grupo Escolar, o qual, por meio do Decreto n. 7.968, passou a denominar-se "Grupo Escolar Raul Soares". O mesmo Decreto autorizou o funcionamento do segundo Grupo Escolar de Araguari: "Visconde de Ouro Preto".

De acordo com os estudos de Gatti, Inácio Filho e Gatti Júnior (2011), nos anos de 1920, na cidade de Uberlândia, assim como em nível nacional, era veiculado o discurso da educação como o caminho para o progresso. Com resposta a esse discurso, em 1922, o "Gymnásio de Uberabinha" passou a funcionar em nova sede, agora mais ampla e atuou como instituição privada até 1928. O Colégio Amor às Letras e o Externato Violeta foram fundados em 1918. Foi criado, em 1919, o Instituto Fundamental, em 1920. Em 1924, foram instalados o Colégio Santa Rita de Cássia, o Externato Spenser e a Escola Normal, que era um anexo do Ginásio de Uberabinha. Ainda em 1924, foi instituída a Associação Brasil Central de Educação e Cultura, mais conhecida como ABRACEC. O Liceu de Uberlândia foi fundado em 1928, em regime de internato e externato. Em 1929, o Ginásio de Uberabinha foi estadualizado, por meio do Decreto $\mathrm{n}^{\circ}$ 8958, de 03 de janeiro de 1929, tendo seu prédio sido doado ao Estado sem nenhum ônus, com a denominação de Ginásio 
Mineiro de Uberabinha. Os estudos dos autores comprovam o predomínio do ensino privado na cidade de Uberlândia, fato que espelha a realidade nacional nesse período.

Segundo os estudos de Coelho (2007), em 1929, foi fundado, em Patos de Minas, o Instituto Sul-Americano, com curso ginasial, que foi oficializado em 1930. Conforme a autora, o Instituto teve curta duração, porém serviu como estabelecimento oficial para a escola Normal Oficial, que foi a pioneira do ensino médio na cidade de Patos. Foi criada pelo Decreto n. 10310, de 02 de abril de 1932.

Quanto ao ensino nas escolas localizadas no meio rural, nos municípios investigados, no final dos anos 1920, não encontramos nenhum trabalho que se detenha nesse contexto, as pesquisas de Ribeiro (2009), Silveira (2008), Sales (2007) e Silva Júnior (2007), ao apresentarem um panorama da história da educação, revelam que prevalecia o descaso com a educação rural, evidenciando algumas dificuldades: problemas na formação dos professores, com os prédios, mobiliários, infrequência escolar, dentre outros.

\section{A escolarização nos anos de 1930 até 1960}

Ao analisar o contexto nacional entre os anos de 1930 a 1937, caracterizado pela industrialização/urbanização, Zotti (2004) ressalta que a educação escolar foi-se fazendo necessária a um número maior de pessoas, dada a complexificação do campo econômico, político e cultural. Nesse período, instaurou-se um amplo debate político educacional entre católicos, liberais e governistas. De acordo com a autora,

Ao ensino defendido pelos católicos, alicerçado na pedagogia tradicional, nitidamente elitista, defendendo a manutenção da ordem econômica e política vigente na Primeira República, opunham-se os educadores liberais. Esses defendiam a pedagogia da Escola Nova e a construção de um país em novas bases econômicas e políticas, de acordo com o modelo urbano-industrial. (p. 88).

Os pontos principais no debate entre católicos e liberais referiam-se à laicidade, à defesa da escola pública obrigatória e gratuita e à coeducação dos sexos com direito de igualdade. De acordo com Zotti (2004), os liberais tinham como princípio o direito de todos à educação, e esta deveria ser assegurada pelo Estado, dessa forma, pública e gratuita, além de ser laica. A Igreja católica, até então, monopolizadora do ensino médio, privilégio da elite, que pagava pelo ensino, ameaçada pela possibilidade de esvaziamento das escolas privadas, tomou partido pela velha ordem, e com isso, pela educação tradicional.

Com a aprovação da Constituição de 1934, o governo Vargas procurou conciliar a proposta entre católicos e liberais, pois todas as propostas dos liberais foram adotadas, mas o governo atendeu a alguns aspectos defendidos pelos católicos, entre eles, o retorno do ensino religioso facultativo no currículo escolar. Outra mudança promovida por essa Constituição foi que o Estado passou a assumir a função de traçar as diretrizes da educação nacional, que, segundo Zotti (2004), tiveram um caráter profundamente centralizador.

Quanto à Constituição de 1937, no período da ditadura Vargas, podemos identificar traços diferentes, se comparada com a Constituição de 1934, pois desobrigou o Estado da educação pública, limitando-se ao papel de subsidiar a educação. Segundo o artigo 129, era dever das indústrias e dos sindicatos econômicos criar, na esfera da sua especialidade, escolas de aprendizes, destinadas aos filhos de seus operários ou de seus associados. O artigo 130 definia que o ensino primário era obrigatório e gratuito. A gratuidade, porém, não excluía o dever de "solidariedade" dos menos para com os mais necessitados; assim, 
por ocasião da matrícula, era exigido aos que não alegassem, ou notoriamente não pudessem alegar escassez de recursos, uma contribuição módica e mensal para a caixa escolar. A análise da Constituição de 1937 revela outra característica marcante: a dualidade educacional, pois enfatiza o trabalho manual. Dessa forma, os ricos tinham acesso à educação propedêutica, enquanto aos pobres restavam as escolas profissionalizantes.

Em 1945, com a redemocratização do país, os movimentos populares tomaram força, e a aprovação da Constituição de 1946 retomou um aspecto fundamental: o princípio da educação como direito de todos, a escola primária obrigatória, a assistência aos estudantes, a gratuidade do ensino oficial para todos ao nível primário e, aos níveis ulteriores, para quantos provassem falta ou insuficiência de recurso materiais. Nesse contexto, foi discutida a elaboração da primeira LDB, que foi somente aprovada em 1961. Para Zotti (2004), a educação, entre 1961 e 1964, teve seu investimento aumentado em $5,93 \%$ e, em 1962, de acordo com a LDB n. 4.024/61, o governo lançou o Plano Nacional de Educação - PNE, que determinava o investimento de, no mínimo, $12 \%$ dos recursos dos impostos arrecadados pelo governo federal. Tais transformações podem ser entendidas como resultado das organizações de trabalhadores, mobilizações de estudantes, organizações sindicais, enfim, resultado de pressões da sociedade civil.

Se considerarmos as especificidades do campo e as transformações ocorridas na educação escolar no meio rural, o período entre 1930 a 1964 não registrou grandes mudanças efetivas no cenário nacional. A Constituição de 1934 apresenta, no artigo 156, que a União deveria reservar, no mínimo, vinte por cento das cotas destinadas à educação, no respectivo orçamento anual, para a realização do ensino nas zonas rurais. O PNE, de 1934, definiu, para o meio rural, uma política pautada no controle do êxodo rural e na aculturação do homem do campo. Outro aspecto do PNE foi a descentralização, em que a responsabilidade pelos níveis de ensino foi dividida entre a União, Estado e Municípios. O Estado de Minas Gerais, assim como os demais Estados Federados, ficou responsável pelo ensino primário, ginasial e secundário; e a rede de ensino no meio rural passou a ser responsabilidade dos municípios.

Quanto à Constituição de 1937, nada mencionou sobre a educação no meio rural. Nesse contexto, segundo Leite (1999), foi criada a Sociedade Brasileira de Educação Rural, com objetivo de expansão do ensino e preservação da arte e folclore rurais. Em 1942, a escolarização rural foi reforçada durante o VIII Congresso Brasileiro de Educação, porém, de acordo com Leite (1999), não se definiram, claramente, os óbices da educação rural. A Constituição de 1946 também silenciou sobre a questão no meio rural. Quanto à LDB 4.024/61, Flores (2000) afirma que o processo de tramitação da Lei acirrou as discussões a respeito da responsabilidade do Estado para com a educação do país. Porém o debate que se configurou nesse período não foi suficiente para garantir as escolas para o meio rural. Sobre essa Lei, Leite (1999) declara que, ao deixar a cargo das municipalidades, a estruturação da escola fundamental no meio rural foi omitida, uma vez que a maioria das prefeituras municipais do interior era desprovida de recursos humanos e financeiros. Com a negligência do Estado em relação às escolas rurais, as próprias comunidades se organizaram para criar escolas e assegurar a educação de seus filhos, contando, algumas vezes, com o apoio da Igreja, de outras organizações e movimentos sociais comprometidos com a educação popular.

Ao determos nosso olhar nos municípios de Araguari, Uberlândia e Patos de Minas, no período entre 1930 a 1960, podemos identificar reflexos da política nacional. Conforme Silva Júnior (2007), na cidade de Araguari, em novembro de 1943, foi fundada a Escola de Comércio, denominada Escola Técnica de Comércio Machado de Assis e Ginásio Dom Vidal, que, no início, oferecia apenas o curso comercial básico seguido pelo curso ginasial. 
Em 1946, iniciou-se o curso Técnico de Contabilidade. Essa escola refletia a proposta da escolaridade voltada para a capacitação profissional, que caracterizou a política do Estado Novo. Por evidenciar um crescimento populacional, foi necessária, na cidade de Araguari, a construção de mais escolas públicas: Escola Estadual Costa Sena, em 1955; Escola Estadual Professor Antônio Marques, em 1957; Escola Estadual e Escola Estadual Paes de Almeida, em 1959.

Na cidade de Uberlândia, nesse período, Gatti, Inácio Filho e Gatti Júnior (2011) registraram a criação de diversas escolas: Academia de Comércio de Uberlândia, em 1931; Externato Santa Luzia e Grupo Escolar Minas Gerais, em 1932; Externato Espírito Santo, em 1933; Externato Rio Branco, Externato Nossa Senhora Aparecida e Externato Senhora do Carmo, em 1934; Externato São Sebastião, em 1935; Escola de Uberlândia, em 1936; Em 1939, foram instalados os seguintes externatos: Externato Nossa Senhora de Lourdes, Externato Sete de Setembro, Externato Santa Maria, Externato Brasil, Externato Santa Clara, Externato Santa Inês; Ginásio Osvaldo Cruz, em 1942. De acordo com os autores, prevalecia, em Uberlândia, o ensino privado, demonstrando o descaso do Estado com a educação pública na região.

Segundo Coelho (2007), em Patos de Minas, no ano de 1939, foi criado o Ginásio Municipal de Patos de Minas. Após a chegada das irmãs sacramentinas na cidade, em 1945, o estabelecimento passou por transformações e, em 1947, foi criado o curso normal. Nesse contexto, ainda compuseram o cenário educacional de Patos de Minas: Grupo Escolar Santa Terezinha, fundado em 1947; Grupo Escolar Professor Modesto, em 1954; Escola Técnica Pio XII, em 1956; Grupo Escolar Cônego Getúlio, em 1958; Colégio Municipal de Patos de Minas e Grupo Escolar Monsenhor Fleury, em 1959.

Quanto às escolas localizadas no meio rural, nos municípios, lócus desta investigação, integravam o quadro da educação escolar do meio rural brasileiro, ou seja, relegadas a segundo plano. Silveira (2008) informa que, em 1930, o município de Uberlândia contava com três escolas rurais; em 1953, esse número passou para 51 (cinquenta e uma) escolas. Para a autora, o crescimento quantitativo de escolas era reflexo do ideário de "progresso" comum em nível nacional e muito bem incorporado ao município de Uberlândia. A proposta de ensino era não evidenciar o rural, a notoriedade pertencia ao espaço urbano, símbolo de desenvolvimento, progresso e civilidade. Os estudos de Ribeiro (2009) denunciam que não havia preocupação com a qualidade de ensino na escola rural, que eram instaladas em qualquer lugar, independente das condições de higiene para abrigar os alunos. Segundo a autora, muitos "prédios" eram oferecidos pelos fazendeiros, pois essa era uma das poucas alternativas para "funcionar" uma escola no meio rural. De acordo com Silva Júnior (2007), no município de Araguari, a precarização da escola rural se fazia presente. As escolas municipais, nesse período (19301960), também funcionavam de forma improvisada, muitas vezes, em antigos barracões, currais desativados, oferecidos pelos proprietários das fazendas. Na década de 1950, foram criadas pelo Estado de Minas Gerais duas escolas localizadas nos distritos de Piracaíba e Amanhece: Escola Estadual Coronel Lindolfo Rodrigues da Cunha, em 1955, e Escola Estadual Artur Bernardes, em 1956.

\section{A escolarização nos anos da ditadura militar}

Com o golpe militar, em 1964, a política educacional passou a sofrer um processo de mudanças. Os canais de participação e representação popular foram fechados, impedindo, assim, a manifestação dos grupos envolvidos. Houve a perseguição, prisão e exílio de educadores comprometidos com projetos de educação popular. Pelos estudos de 
Zotti (2004), o Estado se descomprometeu, gradativamente, de financiar a educação pública, pois os recursos estavam comprometidos com o capital privado, repassando, assim, verbas para as escolas particulares. A grande parcela da população não tinha sequer acesso à educação básica, a iniciativa privada dominava o pré-escolar, crescia no segundo grau e era majoritária no ensino superior. A Constituição de 1967, no campo da educação, assegurou o fortalecimento do ensino particular. Segundo a autora,

O Estado adota o discurso de valorização da educação escolar, mas permanece nele, pois as verbas para a educação pública são escassas, enquanto o governo aplica um montante elevado no setor educacional privado, apontando para o caminho da privatização do ensino. (...) Também subordina a educação à produção capitalista, segundo a Teoria do Capital Humano, adotando uma concepção tecnicista de educação. (p. 143).

A concepção tecnicista da educação, nesse período, foi assegurada por meio da Lei 5.692/71. Essa Lei, que passou a regulamentar a educação básica, foi elaborada e aprovada em um clima desprovido de mobilizações relativas à questão específica da educação e cultura. Esse fato pode ser entendido em virtude da aprovação do Ato Institucional n. 5 AI5, em dezembro de 1968. Esse Ato Institucional garantia plenos poderes ao presidente da República, podendo legislar em todas as matérias e impedir o funcionamento do Judiciário. O Estado atingiu o mais elevado grau de autonomia, permitindo até mesmo prisões arbitrárias, torturas e assassinatos de presos políticos. Também instituiu a censura na imprensa e passou a controlar as universidades e instituições educativas. Os poucos espaços de liberdade, presentes no texto constitucional, foram eliminados.

De acordo com o Art. $1^{0}$, da Lei 5.692, de 11 de agosto de 1971 , o ensino de $1^{0}$ e $2^{0}$ graus tinha por objetivo geral proporcionar ao educando a formação necessária ao desenvolvimento de suas potencialidades como elemento de autorrealização, qualificação para o trabalho e preparo para o exercício consciente da cidadania. Ao analisarmos a referida Lei, concordamos com Leite (1999), ao afirmar que a educação rural, mais uma vez, não foi focalizada ou enfatizada, mas pior, foi destituída de sua identidade. Essa reforma educacional, centralizada e excludente, baseou-se no binômio segurança nacional e desenvolvimento econômico. Identificando algumas intenções implícitas da Lei Federal 5.692/1971, podemos citar a utilização do processo escolar, em todos os níveis de escolaridade, como meio de propagação, divulgação e penetração do ideário nacionalistamilitar do Estado, isto é, fazendo prevalecer a ideologia empresarial-estatal; controle político-ideológico-cultural, principalmente da classe operária, por meio da profissionalização e do currículo escolar mínimo, desprovido de um conteúdo críticoreflexivo; recriação de infraestrutura material e de recursos humanos adequados ao desenvolvimento do capital e da produção.

No período da Ditadura Militar, evidenciamos um grande número de escolas isoladas no meio rural mineiro. Silva Júnior (2007) esclarece que, no município de Araguari, no ano de 1973, funcionavam 71 (setenta e uma) escolas rurais. Porém mantinhase a mesma precarização, cada fazenda improvisava uma sala de aula multiseriada, para atender os filhos dos trabalhadores rurais. Segundo Flores (2000), a escola rural isolada significou economia de dinheiro público. No caso, a economia se dava por meio da exploração do trabalho do professor, que, além de mal remunerado, assumia a função de docente, faxineiro, diretor, coordenador, cozinheiro e secretário. Nesse contexto, podemos identificar a permanência de alguns problemas da educação escolar no meio rural mineiro: salas multisseriadas, número reduzido de alunos, difícil acesso tanto para professores 
quanto para alunos, professores não qualificados, inexistência de condições físicas e de pessoal que garantissem um funcionamento razoável das escolas.

O cenário da educação escolar no meio rural mineiro, ao longo da década de 1970, evidenciou o que ocorria no cenário brasileiro. Foi um momento fértil de produção de pesquisas, projetos de capacitação e elaboração de materiais pedagógicos para as escolas. A maior parte desses materiais visava à diminuição do êxodo rural e dos índices de analfabetismo. Porém, segundo Silva (Silva et.al, 2008), não foram inseridas, nessas políticas, modificações na gestão das escolas. Nesse contexto, pelo menos no estado de Minas, entravam em cena, com muita força, os movimentos sociais, que reivindicavam uma escola direcionada para a realidade do campo. Uma das consequências dessa luta foi a criação, em Minas Gerais, das Escolas Família Agrícola.

A Escola Família Agrícola surgiu, no Brasil, sob a inspiração dos Centros Familiares de Formação por Alternância, de origem francesa. Sua implantação no País teve início no Espírito Santo, em 1968, com a criação da Escola Família Agrícola de Olivânia, no município de Anchieta. Buscava-se, com esse movimento, não apenas a fixação do jovem instruído no campo, mas, fundamentalmente, conscientizá-lo de sua função política junto à história do seu grupo social. De acordo com Aranha (Aranha, et.al, 2007), em Minas Gerais, existiam, no ano de 2008, 15 (quinze) escolas em 14 (quatorze) localidades.

Segundo Aranha (Aranha, et.al, 2007), a implementação das primeiras experiências de escolarização em conformidade com a Pedagogia da Alternância, em Minas Gerais, esteve relacionada com o movimento social e eclesial no final dos anos de 1970 e início dos anos de 1980. Os princípios basilares dessa modalidade pedagógica eram: a) a constituição de uma associação de pais, responsáveis por todas as questões relativas à escola; b) a alternância de etapas de formação entre a Maison Famíliale e a propriedade familiar como preceito norteador da prática pedagógica; c) a composição de pequenos grupos de jovens (12 a 15 anos) sob a responsabilidade de um monitor, com possibilidade de aplicação dos princípios pedagógicos da alternância; d) a formação completa da personalidade, dos aspectos técnicos aos morais e religiosos; e) o desenvolvimento local sustentável como horizonte a nortear a relação homens e meio ambiente.

Registramos, nas cidades investigadas, algumas mudanças que evidenciam a tentativa de efetivação da proposta educacional do governo militar. Na cidade de Araguari foi fundada em 1972, a Escola Estadual Madre Maria Blandina, chamada de Polivalente. As escolas polivalentes surgiram como proposta do Governo Federal para expansão do ensino médio e para o atendimento dos filhos de trabalhadores, a proposta era de um ensino profissionalizante. Em 1974, a escola deixou de pertencer à Federação e passou para a rede estadual. Os professores tinham sido "treinados" para o projeto específico, e muitos não tinham nem sequer habilitação, receberam a titulação do Governo Federal, revelando o caráter tecnicista da educação. Esses professores, com a falência do projeto, migraram para a rede estadual. Além do polivalente, outras escolas foram fundadas na cidade de Araguari: Escola Estadual Rainha da Paz e Escola Estadual Dona Eleonora Pieruccetti, em 1964; Escola Estadual São Judas Tadeu, em 1967; Escola Estadual Padre Eloi, em 1980 e a Escola Estadual José Carneiro da Cunha, em 1983. Até por volta dos anos de 1980, as escolas públicas não eram suficientes para o número de alunos. Para ter acesso à escola pública, era necessária a realização de exames seletivos e só os mais bem classificados tinham direito à vaga. Em 1968, foi instalada a primeira instituição de nível superior, a Faculdade de Filosofia, Ciências e Letras de Araguari - FAFI.

$\mathrm{Na}$ cidade de Uberlândia, por meio do Parecer n. 141/75, foi aprovado o funcionamento do segundo grau na Escola Estadual Américo René Giannetti, com habilitações em Técnico em Edificações, Técnico em Eletrônica, Técnico em 
Eletrotécnica, Técnico em Mecânica, Técnico em Secretariado, Técnico em Economia Doméstica, Auxiliar em Documentação Médica e Modelador de Calçados. A proposta limitava-se a formar mão de obra técnica profissionalizante para o mercado de trabalho, correspondendo ao objetivo da Lei 5.692/71. Em Uberlândia, segundo Ramos (2010) e Garcia (2011), passou a funcionar efetivamente, em 1969, a Escola Agrotécnica de Uberlândia. O objetivo era formar técnicos agrícolas de nível médio. De acordo com Garcia (2011), também foi instalada a Escola Estadual Polivalente Guiomar de Freitas, em 1971 e o Serviço Nacional de Aprendizagem Industrial - SENAI -, em 1977. Em nível superior, foi criada, em 1969, a partir da fusão de faculdades isoladas, e federalizada em 1978, a Universidade Federal de Uberlândia - UFU.

Na cidade de Patos de Minas, segundo Sales (2007), foi construída a Escola Polivalente Professora Elza Carneiro Franco, que oferecia, entre outros cursos, o ensino agrotécnico. Porém, conforme a autora, não foram percebidas alterações no setor agropecuário da cidade com a implantação do curso, nem tampouco atendia a alunos provenientes do meio rural. Destacamos, também, a criação da Fundação Educacional de Patos de Minas - FEPAM em 1968. Segundo Rassi (2006) a conjuntura da criação da FEPAM, se insere no contexto da política nacional. O Governo Federal engendrava e implementava estratégias de despolitizar a universidade, promovendo o afastamento e a aposentadoria compulsória de professores e cientistas, que de alguma forma, incentivavam o debate crítico de oposição ao regime militar. De acordo com o autor, no bojo dessas mudanças, é arquitetada a Reforma Universitária, outorgada por meio da Lei 5.540/68, que visava arrefecer os protestos estudantis e os partidos no interior das universidades, vislumbrando a formatação do ensino superior no Brasil, em busca de uma orientação mais tecnicista.

\section{A educação escolar no período de redemocratização do país}

As transformações ocorridas no cenário econômico brasileiro do século $\mathrm{XX}$ passaram a exigir da escola uma participação cada vez mais efetiva na educação das novas gerações. As mudanças no mundo do trabalho redimensionaram - ora limitando, ora dificultando - o papel da família na educação dos filhos, ocorrendo a transferência dessa responsabilidade para a escola e seus professores. Ao mesmo tempo, verificava-se uma inibição educativa de outros agentes de formação, tais como a Igreja e os movimentos sociais e culturais. Tudo isso vem aumentando a responsabilidade da escola e de seus professores como espaço e sujeitos de socialização e formação dos indivíduos para a vida em sociedade.

A educação escolar passou, ao longo do século XX, a ser um direito universal dos homens. Em 1984, encerrou-se o longo ciclo dos militares no poder, iniciou-se, no país, o processo de redemocratização. Na educação, a luta é pela universalização do ensino. As conquistas começaram a se tornar realidade com a aprovação da Constituição Federal de 1988 e com a Lei de Diretrizes e Bases da Educação Nacional - LDB 9394/96. De acordo com o Artigo 212 da Constituição Federal, aprovada em 1988,

A União aplicará, anualmente, nunca menos de dezoito, e os Estados, o Distrito Federal e os Municípios vinte e cinco por cento, no mínimo, da receita resultante de impostos, compreendida a proveniente de transferências, na manutenção e desenvolvimento de ensino.

A partir da promulgação da Constituição de 1988, ocorreram mudanças como nucleação das escolas rurais ${ }^{4}$ e a municipalizaçãa ${ }^{5}$. Outras possibilidades para a escola 
rural começaram a ser pensadas de acordo com uma perspectiva crítica. Iniciativas diferentes, situadas no campo da educação popular, da política, da educação de jovens e adultos, passaram a exigir maior participação do Estado no meio rural brasileiro. Essas discussões acentuaram-se com o debate e a aprovação da Lei de Diretrizes e Bases da Educação Nacional (LDB 9394/96), que estabelece no artigo 28:

Na oferta da educação básica para a população rural, os sistemas de ensino promoverão as adaptações necessárias a sua adequação às peculiaridades da vida rural e de cada região, especialmente:

I - conteúdos curriculares e metodologias apropriadas às reais necessidades e interesses dos alunos da zona rural;

II - organização escolar própria, incluindo adequação do calendário escolar às fases do ciclo agrícola e às condições climáticas;

III - adequação à natureza do trabalho na zona rural.

Propostas de adequação da escola à vida do campo não estavam contempladas anteriormente na sua especificidade. Segundo Leite (1999), a LDB/1996 promoveu a desvinculação da escola rural dos meios e da performance escolar urbana, exigindo da escola rural um planejamento ligado à vida rural e, de certo modo, desurbanizado. No entanto, mesmo diante das mudanças previstas pela referida Lei, as problemáticas ligadas à escola rural permaneceram. Leite (1999) sinalizava alguns problemas recorrentes nos anos 1990. Quanto aos alunos da escola rural, o autor destacou a distância entre os locais de moradia/trabalho/escola e o acesso precário a informações gerais. A respeito da participação da comunidade no processo escolar, registrou o distanciamento dos pais em relação à escola, embora as famílias tenham a escolaridade como valor sociomoral. Quanto à ação didático-pedagógica, o autor acentuou a inadequação do currículo, geralmente, estipulado por resoluções governamentais, com vistas à realidade urbana.

Com o propósito de mudar as políticas educacionais, na última década do século XX e início do século XXI, houve uma instigante presença dos sujeitos do campo na cena política e cultural do País. Os movimentos sociais denunciavam o silenciamento e o esquecimento de suas realidades por parte dos diversos órgãos governamentais e lutavam por uma escola do campo que não fosse apenas um arremedo da escola urbana, mas que estivesse atenta às especificidades dos seus sujeitos.

Nessa perspectiva, o debate sobre a educação do campo, no âmbito do estado de direito, como demanda e estratégia de luta pela emancipação e cidadania dos sujeitos que vivem ou trabalhem no campo, vem ganhando espaço. As estratégias visam colaborar para a formação das crianças, jovens e adultos em direção a um desenvolvimento sustentável regional e nacional. Assim, as propostas têm como princípio a valorização dos saberes que a população rural produz nas suas experiências cotidianas, e a agenda de trabalho, para discutir e subsidiar a construção de uma política de educação do campo, passa a incorporar o respeito à diversidade cultural.

No meio rural brasileiro, particularmente no lócus da pesquisa, evidenciamos que os responsáveis pela educação escolar deparam-se com as mais diversificadas formas de processos produtivos, culturas heterogêneas, sujeitos diferentes dos que estão acostumados na cidade, com valores e aspirações próprios. Nessa óptica, faz-se necessário romper com a visão preconceituosa de que o meio rural é um espaço atrasado, de ignorância, sem cultura, sem vida, sem identidade. Nessas circunstâncias, mais do que fazer um "remendo", é 
preciso humanizar e legitimar as dimensões políticas e pedagógicas da educação básica no meio rural.

Pensar a educação em escolas no meio rural brasileiro é pensar em estratégias que ajudem a reafirmar identidades. Nesta perspectiva, é pertinente ressaltar o protagonismo do MST nos debates e nas demandas por políticas públicas. De acordo com Lucini (2007), o MST é um dos movimentos sociais do campo que, na história do Brasil, sobressai pelas suas ações, conquistas e, sobretudo, pela sua organização. É um movimento que cresceu e fortaleceu-se de tal forma, que suas ações têm desafiado a suposta "ordem" social, econômica e cultural. Tem tido a capacidade de reiventar-se politicamente. A autora define o MST como grupo da sociedade civil que se organiza e assume a história no sentido de fazê-la acontecer. Conduz, pela sua força social, os processos de transformação, não espera soluções do Estado, mas faz a história.

No caso da educação no meio rural, o MST contribuiu para grandes conquistas. Uma delas é o Parecer n. 36/2001, que propõe medidas de adequação à vida no campo. Outra conquista foi a instituição das Diretrizes Operacionais para a Educação básica nas Escolas do Campo, aprovada pelo Conselho Nacional de Educação - Resolução CNE/CEB, n. 1, de 03 de abril de 2002. O documento é fruto da ação do Grupo Permanente de Trabalho de Educação do Campo (GPTE), que consolidou reivindicações históricas das organizações e dos movimentos sociais que lutam por uma educação de qualidade para os diversos sujeitos, com identidades diversas, que vivem no campo, como: agricultores familiares, trabalhadores rurais sem terra, quilombolas, assalariados rurais, povos da floresta, ribeirinhos, pescadores, extrativistas e outros. Ressalta-se que, em fevereiro de 2004, no contexto do governo Lula, por demandas dos Movimentos Sociais, criou-se, na estrutura do Ministério da Educação e Cultura (MEC), a Secretaria de Educação Continuada, Alfabetização, Diversidade e Inclusão (SECADI) ${ }^{6}$, que conta com a Coordenação Geral da Educação no Campo.

Ao focarmos nosso olhar sobre os municípios investigados, verificamos que em Araguari, até 1992, 42 escolas municipais rurais passaram pelo processo de nucleação. Foram construídas 6 escolas rurais nucleadas em pontos geográficos estratégicos. A permanência das duas escolas estaduais, em Araguari, no meio rural, mesmo depois do processo de municipalização, deu-se em função da lutas das comunidades escolares (Piracaíba e Amanhece) contra esse processo, pois alegava-se que a rede municipal não estava preparada para manter, com qualidade, todo o ensino fundamental, e por não ser obrigação do município a manutenção do ensino médio.

Em Patos de Minas, segundo Sales (2007), entre os anos de 1990 a 1992, foi iniciado o processo de nucleação das escolas rurais, período em que existiam 69 escolas rurais. De 1993 a 1996, esse processo continuou, mas de forma mais lenta, e foram iniciados dois projetos destinados à educação campesina: Projeto "Classes Multisseriadas" e Projeto "Classes Seriadas", que buscavam "resgatar" a cultura imediata dos alunos como ponto de partida do processo de ensino e aprendizagem. Entre 1997 a 2000, o governo municipal de Patos de Minas investiu na construção de novos prédios e acelerou o processo de nucleação, terminando esse período com 100\% das escolas nucleadas. Em 2010, eram oito unidades de educação infantil/pré-escolar e de ensino fundamental pertencentes ao município, nucleadas nas localidades rurais de maior densidade demográfica. (DUARTE e GUEDES, 2006, p. 37). Em três distritos de Patos de Minas: Bonsucesso, Santana dos Patos e Major Porto, o ensino fundamental permaneceu atendido pela Rede Estadual de Educação. Além disso, a Rede Estadual assegurava o ensino médio em seis distritos (Alagoas, Bonsucesso, Santana dos Patos, Major Porto, Pindaíba e Areado). 
Em Uberlândia, havia, no ano de 2010, 13 escolas nucleadas, situadas em diferentes localidades, no meio rural, que atendiam da pré-escola até os anos finais do ensino fundamental. Para concluir o ensino médio, a maior parte dos alunos tinha que se deslocar para escolas situadas no meio urbano. A rede estadual mantinha essa modalidade de ensino em apenas dois distritos, Martinésia e Miraporanga, oferecida em anexos da Escola Estadual José Inácio de Souza sediada na cidade. Na Rede Federal, funcionava uma Unidade de Ensino na Fazenda Sobradinho, na qual havia 351 alunos no curso integrado (médio + técnico); 181 no pós-médio; 163 no curso superior, nos cursos de Tecnologia em Alimentos e Tecnologias em Sistemas para Internet.

Se, por um lado, a nucleação contribuiu para minimizar problemas, por outro, gerou outros: cansaço dos alunos devido ao longo tempo de deslocamento gasto para chegar às escolas utilizando o transporte escolar; impossibilidade de participar de atividades extras no ambiente escolar, em razão da distância que separa residência e estabelecimento escolar. Além disso, a dificuldade dos pais em participarem de comemorações, reuniões e diversos eventos promovidos pela escola. Dessa forma, o pequeno contato dos pais com os professores resulta em dificuldades.

Constatamos que os currículos das escolas rurais de Araguari e Uberlândia, em 2010, correspondiam aos das escolas urbanas, não eram consideradas as especificidades do meio rural. Nessas escolas, observamos o fluxo decrescente de alunos, indícios de desinteresse e desempenho escolar insatisfatório, além de baixa autoestima por parte de muitos alunos. Ao propormos considerar o singular, as especificidades, não defendemos o retorno do ruralismo (uma educação no campo que se limite a formar trabalhadores rurais), mas a necessidade de valorizar os saberes locais e as vivências dos jovens estudantes ${ }^{7}$. Acreditamos ser pertinente que os alunos se identifiquem com o espaço escolar, que não sejam negadas suas identidades, assim como dos fios que as tecem. É possível que a escola valorize os meios sobre os quais se assenta a existência social dos jovens estudantes, ou seja, um conjunto de coisas e pessoas comuns portadoras de significados, como terra, casa, posses, empregos e outros marcos divisórios cotidianos.

Nessa perspectiva, destacamos uma experiência do município de Patos de Minas, que promoveu, no período de 2001 a 2004, o programa de desenvolvimento sustentável, denominado, "Projeto de Educação Família Rural (EDUFARURAL)". O Projeto fundamentava-se no referencial de educação de Paulo Freire, cujas bases conceituais e estratégias pedagógicas visavam à valorização das identidades do homem e da mulher do campo. O ponto de partida foi o contexto natural, social e econômico do aluno, sua vivência cotidiana e sua cultura. Com base no mundo do educando, pretendeu-se que os professores empregassem palavras, expressões e temas geradores que norteassem o ensino e desencadeassem o processo de aprendizagem com lastro no cotidiano dos estudantes. $\mathrm{O}$ Projeto foi considerado exitoso, mas as mudanças no poder executivo levaram a modificações na efetivação do EDUFARURAL, que passou a funcionar como uma disciplina na grade curricular das escolas localizadas no meio rural. Em 2010, a "disciplina EDUFARURAL" era trabalhada uma vez por semana.

Sobre o Projeto, Duarte e Guedes (2006) concluíram que o comprometimento do Poder Público é especialmente necessário, mas, por si só, não é suficiente. A experiência de Patos de Minas evidenciou que a administrações municipais ainda têm muito a aprender e se aprimorar em termos de mobilização social e vinculação das políticas públicas aos interesses e às especificações que partem do tecido social. 


\section{Considerações finais}

Ao realizarmos nosso estudo sobre o processo histórico da escolarização nos municípios de Araguari, Uberlândia e Patos de Minas, procuramos não perder de vista a relação com o macro, a interdependência entre "local" "global". Como nos ensinam Nosella e Buffa (1996), não se pode permitir que a descrição pormenorizada das árvores impeça a compreensão da floresta em seu todo. Para Araújo e Inácio Filho (2005), a singularidade da história local ou regional não pode pretender substituir a perspectiva da totalidade da qual faz parte. As transformações no processo de escolarização, do lócus da pesquisa, evidenciam algumas particularidades e diferenças, mas foi possível perceber semelhanças com o que acontecia no Brasil.

Verificamos que, ao longo da história da educação brasileira, a educação dos grupos menos favorecidos fora negligenciada pelo Estado e seus mandatários, e pôde-se perceber que, no meio rural, isso se manifestava de maneira mais intensa. Como marca de uma educação liberal, mesmo sobre a chancela do signo "para todos", a maior parcela da humanidade esteve historicamente à margem do processo educacional, e no Brasil não foi diferente. Conforme nos mostram os estudos de Leite (1999) e do GPTE (2005), da população camponesa foi subtraído o direito de acessar ao conhecimento produzido historicamente pela humanidade e à ciência de seu tempo. Em determinados momentos da história brasileira, sequer tínhamos instituições públicas de ensino no meio rural e quando essas instituições são criadas nesse espaço, resultante das reivindicações da classe trabalhadora, via-se um arremedo de escola erigida sobre estruturas precárias, financiamentos ínfimos e propostas pedagógicas desconectadas das aspirações e das reais necessidades da população camponesa, bem como distanciadas das condições materiais e objetivas do campo.

Acreditamos que aos trabalhadores deve ser ofertada uma educação de qualidade, que a instrução a eles disposta não deve ser inferior àquela posta para os grupos hegemônicos. Não estamos dizendo que aos trabalhadores não foi ofertada nenhuma instrução, mas que a qualidade desta ainda está aquém das suas necessidades. Longe de fazer discussões metafísicas sobre a escola brasileira, podemos elucidar a falta de qualidade da educação a que a classe trabalhadora vem tendo acesso ao longo da história da educação brasileira.

As investidas do capital têm desqualificado o espaço e a instrução oferecida pelo serviço público. Não é difícil perceber suas precárias condições materiais, baixo investimento; precárias estruturas físicas das instituições de ensino; baixos salários dos professores e precárias condições de trabalho; condições insalubres de trabalho; déficit no quadro de professores; currículos cada vez mais esvaziados de conteúdos que são substituídos por competências a serem adquiridas, dentre outras "qualidades". Essa caracterização das escolas públicas brasileiras não são "privilégios" só das escolas rurais, mas também das escolas urbanas.

Defendemos, portanto, uma educação pública de qualidade, urbana e rural, para todos os grupos menos favorecidos que compõem a sociedade brasileira, dentre eles, aqueles que vivem no campo. 


\section{Referências}

ARANHA, Antônia Vitória Soares; ROCHA, Maria Isabel Antunes; CORAGEM, Amarílis Coelho; TEIXEIRA, Inês Assunção de Castro; SOUZA, João Valdir Alves; CORREA, Juliane; CARVALHO, Luzeni F. O.; FARIA, Alessandra Rios. Diálogos entre escola, formação docente e práticas sócio-culturais: possibilidades e limites da Educação do Campo. In: GRACINDO, Regina Vinhaes (org.) (et al) Educação como exercício de diversidade: estudos em campos de desigualdades sócio-educacionais. Regina Vinhaes Gracindo, Carlos Frederico B. Loureiro, João dos Reis Silva Júnior, Márcia Soares de Alvarenga, Marlene Ribeiro, Rosa Helena Dias da Silva (orgs). (et al). Brasília: Líber Livro Ed., 2007.

ARAÚJO, Fátima Maria Leitão. Mulheres letradas e missionária da luz Formação da professora primária nas escolas normais rurais do Ceará - 1930-1960. Tese (Doutorado em Educação). Faculdade de Educação, Universidade Federal do Ceará, 2006.

ARAÚJO, José Carlos Souza. Marcos filosóficos da modernidade em torno da educação da criança: antropologias da infância em disputa? In: ARAUJO, José Carlos Souza; CARVALHO, Carlos Henrique de; MOURA, Esmeralda B. Blanco de. (Orgs.). A infância na modernidade: entre a educação e o trabalho. Uberlândia/MG: EDUFU, 2007.

ARAÚJO, José Carlos; INÁCIO FILHO, Geraldo. Inventário e Interpretação sobre a Produção Histórico-Educacional na Região do Triângulo Mineiro e Alto Paranaíba: da semeadura à colheita. In: GATTI JÚNIOR, Décio; INÁCIO FILHO, Geraldo (orgs.). História da educação em perspectiva: ensino, pesquisa, produção e novas investigações. Campinas, SP: Autores Associados; Uberlândia, MG: EDUFU, 2005.

ARENDT, Hanna . Entre o passado e o futuro. São Paulo: Perspectiva, 1972.

ARROYO, Miguel Gonzalez; CALDART, Roseli Salete; MOLINA, Mônica Castagne. (Orgs.).Por uma educação do campo. Petrópolis, RJ: Vozes, 2004.

AZEVEDO, Fernando de. A transmissão da cultura. São Paulo, Melhoramentos, 1976.

BRASIL. Ministério da Educação - Grupo Permanente de Trabalho de Educação do Campo. Referência para uma política nacional de Educação do Campo. Caderno de subsídios, Brasília, DF, 2005.

COELHO, Leni Rodrigues. Educação de Jovens e Adultos: as ações do Mobral no município de Patos de Minas/MG (1970-1980). Dissertação (Mestrado em Educação). Faculdade de Educação, Universidade Federal de Uberlândia, Uberlândia, MG, 2007.

DUARTE, Elisa Guedes; GUEDES, Vicente. Educação, tecnologia e desenvolvimento rural: relato de um caso em construção. Brasília, DF: Embrapa Informação Tecnológica, 2006.

FARIA FILHO, Luciano Mendes. Conhecimento e Cultura na Escola: uma abordagem histórica. In: DAYRELL, Juarez (org.). Múltiplos Olhares sobre Educação e Cultura. Belo Horizonte: Editora UFMG, 1996.

FLORES, Maria Marta Lopes. Escola Nucleada Rural: Histórico e Perspectivas (Catalão - GO, 1998 - 2000) Dissertação (Mestrado em Educação). Faculdade de Educação Universidade Federal de Uberlândia. Uberlândia, MG, 2000.

GARCIA, Daniela da Costa. História do Colégio Agrícola de Uberlândia, da criação a formatura da primeira turma de técnicos em agropecuária (1957-1972). Dissertação 
(Mestrado em Educação). Faculdade de Educação, Universidade Federal de Uberlândia, Uberlândia, MG, 2011.

GATTI, Giseli Cristina do Vale; INÁCIO FILHO, Geraldo; GATTI JUNIOR, Décio. Urbanização e escolarização na modernização da cidade de Uberlândia: o papel exercido pelas instituições escolares confessionais, particulares e estatais. Disponível em: www.faced.ufu.br/colubhe06/anais/arquivos/35 acesso: 28/07/2011.

LEITE, Sérgio Celani. Escola rural: urbanização e políticas educacionais. São Paulo: Cortez, 1999.

LUCINI, Marizete. Ensinar, aprender e viver história no meio rural. In: FONSECA, Selva Guimarães, GATTI JÚNIOR, Décio (orgs.). Perspectiva do Ensino de História: ensino, cidadania e consciência histórica. Uberlândia: Edufu, 2011.

NOSELLA, Paolo; BUFA, Ester. Schola Mater: a antiga Escola de São Carlos 1911-1933. São Carlos: EDUFSCar, 1996.

RAMOS, Alicia Felisbino. Educação, Trabalho e Formação do Trabalhador de Nível Técnico: Políticas Públicas sobre a Educação Profissional em Uberlândia, MG. Dissertação (Mestrado em Educação). Faculdade de Educação, Universidade Federal de Uberlândia, Uberlândia, MG, 2010.

RASSI, Marcos Antônio Caixeta. Uma canção inacabada: formação de professores de História - experiência da FEPAM (1970-2001). Dissertação (Mestrado em Educação). Faculdade de Educação, Universidade Federal de Uberlândia, Uberlândia, MG, 2006.

RIBEIRO, Cristiane Angélica. Escola rural e alfabetização: Uberlândia 1936 a 1946. Dissertação (Mestrado em Educação). Faculdade de Educação, Universidade Federal de Uberlândia, Uberlândia, MG, 2009.

ROMANELLI, Otaíza de Oliveira. História da educação brasileira: a organização escolar. 15 ed. Campinas, Autores Associados, 1998.

SALES, Suze da Silva. A Educação Rural Brasileira: limites e possibilidades do processo de nucleação em Patos de Minas, MG (1990-2002). Dissertação (Mestrado em Educação). Faculdade de Educação, Universidade Federal de Uberlândia, Uberlândia, MG, 2007.

SILVA JÚNIOR, Astrogildo Fernandes. Saberes e práticas de ensino de História em escolas rurais (um estudo no município de Araguari, MG, Brasil). Dissertação (Mestrado em Educação). Faculdade de Educação, Universidade Federal de Uberlândia, Uberlândia, MG, 2007.

SILVA, Lourdes Helena. et.al. Educação do campo em Minas Gerais - sua história e desafios. Disponível em http://www.faced.ufu.br/colubhe06/anais/arquivos. Acesso em 30 de janeiro de 2008.

SILVEIRA, Tânia Silveira da. História da Escola Rural Santa Tereza (Uberlândia/MG, 1934 a 1953). Dissertação (Mestrado em Educação). Faculdade de Educação, Universidade Federal de Uberlândia, Uberlândia, MG, 2008.

ZOTTI, Solange Aparecida. Sociedade, Educação e Currículo no Brasil: dos jesuítas aos anos de 1980. Campinas, SP: Autores Associados; Brasília, DF: Editora Plano, 2004. 


\section{Notas:}

\footnotetext{
${ }^{1}$ Professor da Faculdade de Ciências Integradas do Pontal - FACIP/UFU

${ }^{2}$ Professor da Faculdade de Ciências Integradas do Pontal - FACIP/UFU
}

${ }^{3}$ A política do café com leite foi caracterizada pelo revezamento do poder nacional executada entre os anos de 1898 e 1930, por presidentes civis fortemente influenciados pelo setor agrário dos estados de São Paulo mais poderoso economicamente, principalmente devido à produção de café - e Minas Gerais - maior pólo eleitoral do país da época e produtor de leite. Revezavam-se no poder representantes do Partido Republicano Paulista (PRP), e do Partido Republicano Mineiro (PRM), que controlavam as eleições e gozavam do apoio da elite agrária de outros estados do Brasil.

${ }^{4} \mathrm{O}$ processo de nucleação caracteriza-se pela união de pequenas escolas isoladas.

5 A municipalização é o processo que consiste em repassar para todos os municípios da União a responsabilidade não só de gerenciar as escolas que ministram o ensino fundamental, mas também garantir o funcionamento desses estabelecimentos.

${ }^{6}$ Em 2004, foi criado a SECAD (Secretaria de Educação Continuada, Alfabetização e Diversidade), em 2008, transformou-se em SECADI (Secretaria de Educação Continuada, Alfabetização, Diversidade e Inclusão). Segundo o MEC, o objetivo da SECADI é contribuir para o desenvolvimento inclusivo dos sistemas de ensino, voltado à valorização das diferenças e da diversidade, a promoção da educação inclusiva, dos direitos humanos e da sustentabilidade socioambiental visando à efetivação de políticas públicas transversais e interssetoriais. Fonte: http://portal.mec.gov.br Acessado em: 20/11/2011.

${ }^{7}$ Um exemplo dessa valorização está registrado na obra: CASTRO, Maurício Barros de. Juventudes rurais: cultura e desenvolvimento. Texto de Maurício Barros de Castro; fotos, Gustavo Stephan - Rio de Janeiro: Instituto Souza Cruz, 2007.

Recebido em janeiro/13

Aprovado em setembro/13 